\title{
An Assessment of Patient's Awareness of Radiation Exposure to Common Diagnostic Imaging Procedures in Low Socioeconomic Regions of Nepal
}

\author{
Ghimire P, Koirala D, Singh BP \\ Department of Radiology and Imaging, Nepalgunj Medical College, Kohalpur, Banke, Nepal \\ Received: January 15, 2016 \\ Accepted: May 20, 2016 \\ Cite this paper: \\ Ghimire P, Koirala D, Singh BP. An assessment of Patient's awareness of Radiation exposure to common diagnostic \\ imaging procedures in low socioeconomic regions of Nepal. Nepalese Journal of Radiology 2017;7(10):9-12.
}

\begin{abstract}
Introduction: Radiological investigations form a cornerstone in the management of patients. Patient might me unware of the radiation exposure. The aim of this study is to assess patient's knowledge of radiation exposure to common diagnostic imaging procedures.

Methods: A cross-sectional study was conducted and questionnaire used to collect data from 216 patients who had undergone radiological investigations.

Results: Among 216 patients, there were 112 (51.85\%) females and 104 (48.15\%) males. The age of the patients ranged from 12 years to 66 years. Only 65 patients $(30.1 \%)$ were aware of the radiation hazards. Neoplasm was the most common side effect chosen by 60 patients. 44 patients were informed of radiation hazards with only 17 patients however informed by the referring doctor. Patients having undergone radiological procedure previously were more aware of radiation hazards (21 patients out of 26 patients).
\end{abstract}

Conclusion: This study showed dearth of knowledge and awareness regarding radiation hazards amongst general public which mandates education.

Keywords: Carcinogenic, Neoplasm, Radiation, Radiosensitive

\section{INTRODUCTION}

Radiological investigations form a cornerstone in the management of patients influencing in the diagnosis, staging, treatment as well as follow up of such cases. ${ }^{1}$ There has been a dramatic surge in the number of

Correspondence to: Dr. Prasanna Ghimire

Department of Radiology and Imaging,

Nepalgunj Medical College,Banke

Email: drprasannaghimire@gmail.com radiological examinations and procedures performed both in developed and developing 
countries. Most radiological investigations however involve radiation exposure which is a serious concern at all age groups and has been a subject of major study. Radiation has significant biological effects which however depend on the dose, duration of exposure besides the various individual factors such as age, gender and pre-morbid states. ${ }^{2}$ In this study, we assessed the level of knowledge and awareness of radiation dose and hazards amongst patient presenting at our institution.

\section{METHODS}

This cross-sectional observational study was carried out in patients who were referred for radiological investigations at the radiology department of Nepalgunj Medical College and Teaching Hospital, Kohalpur, Nepal from March 2015 to August 2015. A questionnaire was devised and was randomly distributed among 216 patients after completion of their radiological investigation to minimize the biasedness from information of our study. Questionnaires were in Nepali and included two sections with first comprising the demographic, educational, socioeconomic status. The second section consisted of questions concerning patient's awareness of radiation hazards. These included knowledge of radiation risk of their and other radiological examinations, whether informed consent and pre-procedural counseling was done, if informed who the individual was providing the information and whether it was adequate/ well informed. In case patient was not informed, questions were asked whether the individual would have performed the same examination if he/ she had been thoroughly informed beforehand. The data were collected and analyzed using SPSS version 16.

\section{RESULTS}

Among the 216 patients, $112(51.85 \%)$ were female and $104(48.15 \%)$ were male with female: male ratio of 1.08:1. The age of the patients ranged from 12 years to 66 years with mean age of years. Only 65 patients were aware of the radiation hazards which included 43 males and 22 females (Figure 1).

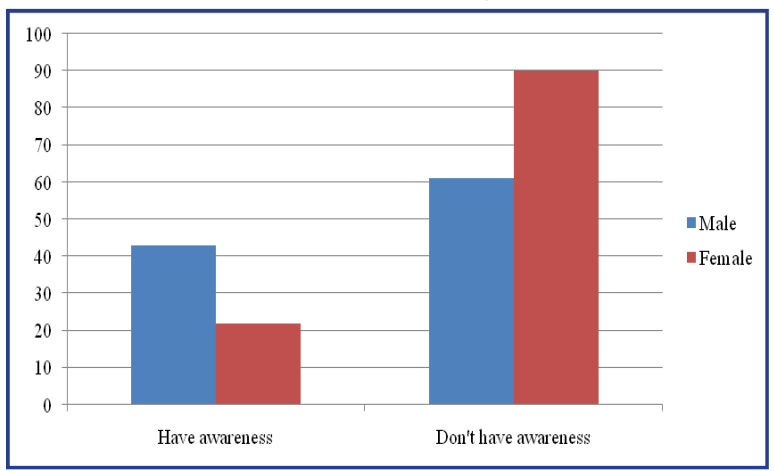

Figure 1: Gender wise awareness of radiation hazards

Neoplasm was the most common side effect chosen by 60 patients. Skin diseases and congenital abnormalities as side effects were chosen by 12 and 9 patients respectively. Most of our patients were uneducated (Figure 2) with low socioeconomic status (Figure 3 ).

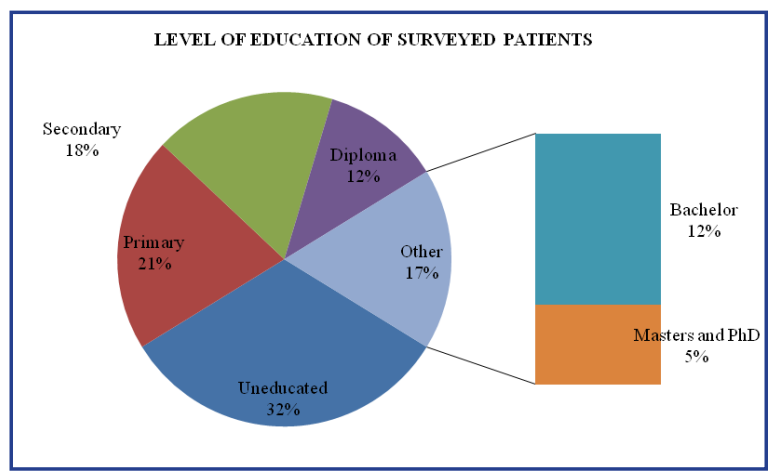

Figure 2: Level of education of surveyed patients

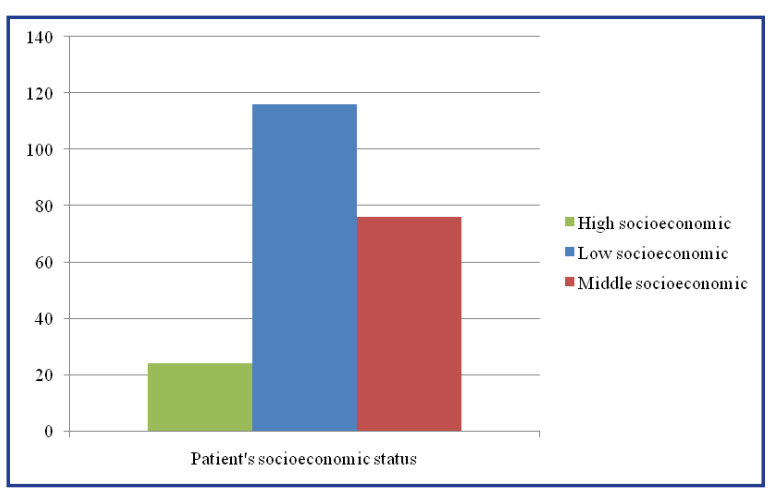

Figure 3: Socioeconomic status of patients 
Forty four patients were informed with only 17 patients however informed by referring doctor. Of the 172 uninformed patients, 98 would accept, 36 wouldn't accept and 38 would hesitate / rethink performing the investigation had they been informed beforehand. Patients who had previously had a radiological procedure were more aware of radiation hazards (21 patients out of 26 patients).

\section{DISCUSSION}

Diagnostic imaging forms an integral part in overall management of patients and there has been an exponentially increased number of radiological investigations in the last two three decades. ${ }^{3}$ Although it has significantly aided in the management; inadvertent radiological imaging poses a great economic burden as well as predisposes to unwanted exposure to the radiations. ${ }^{2}$

In our study, 181 out of 216 patients $(54.6 \%)$ were unaware of radiation hazards which were significantly higher than similar previous studies. ${ }^{4}$ Although some studies have demonstrated an equal or greater knowledge of radiation hazards among females, in our study there was a male preponderance. ${ }^{4,5}$ In our study, awareness of radiation hazards was noted in educated groups however even among the individuals with higher education, majority were unaware of dangers of ionizing radiations. Our study demonstrated that patients who had undergone previous radiological studies were more aware which is in keeping with previous studies. ${ }^{4,6}$ Multiple radiological procedures usually for disease follow up are of concern especially in the pediatric population. Children are more radiosensitive to carcinogenic effects of ionizing radiations and also have longer period for risk expression. ${ }^{7}$ As in few other studies, majority of the radiation hazard aware patients mentioned cancer as the most common radiation related hazard.

In our study, only 44 patients $(25.58 \%)$ were informed of the radiation hazards in their radiological investigation. There are multiple factors attributing to this. Studies have demonstrated that there is death of knowledge of radiation and related health hazards even among medical professionals who are referring as well as those intricately involved in performing radiological investigations. ${ }^{6,8}$ Secondly, ignorance and underestimation of radiation hazards are noted in radiology professionals which is erstwhile not acceptable. $^{9}$

With knowledge of radiation hazards, principle of ALARA (as low as reasonably achievable) has also evolved in medical imaging. It entails that the imaging techniques should be optimized in order to reduce radiation exposure with best image quality. ${ }^{1,10}$ It is detrimental that hospitals follow strict guidelines regarding radiation hazards and health professionals abide by the norms. Government should also form regulatory bodies that timely monitor the facilities.

\section{CONCLUSIONS}

Our study has shown that there is limited knowledge of radiation hazards amongst patients and health professionals. A public radiation awareness programs as well as timely refresher course for radiology/ non radiology medical professionals is mandated to reduce both the economic burden as well as radiation related hazards.

CONFLICT OF INTEREST

None

\section{SOURCES OF FUNDING}

None 


\section{REFERENCES}

1. Amis ES, Butler PF, Applegate KE et al. American College of Radiology white paper on radiation dose in medicine. $\mathrm{J}$ Am Coll Radiol 2007;4(5):272-284. https://doi.org/10.1016/j. jacr.2007.03.002

2. Cohen BL. Cancer risk from low-level radiation. AJR Am J Roentgenol 2002;179(5):1137-1143. https://doi org/10.2214/ ajr.179.5.1791137

3. Knechtges PM, Carlos RC. The evolving role of radiologists within the health care system $\mathrm{J}$ Am Coll Radiol 2007;4(9):626-635. https://doi.org/10.1016/j. jacr.2007.05.014

4. Malik N, Usman F, Fatima S, Jameel G, Trimizi UA. Awareness of hazards of Radiation in patients visiting Radiology department of Social Security hospital Islamabad. Rawal Med J 2014;39(4):372-375. Available from: https://www.ejmanager. com/fulltextpdf.php?mno=166434 [Accessed 20th December 2015].

5. Hagi SK, Khafaji MA. Medical students' knowledge of ionizing radiation and radiation protection. Saudi med $J$ 2011;32(5):520-524. Available from: https://pdfs. semanticscholar.org/fbb8/ b $\quad$ a 7 a 2c3ab3fe264fb7e4a969e7.pdf [Acessed 21st December 2015].

6. Aubaid HN. Patient's awareness of cancer risk from radiation in computerized tomography. Kufa Med Journal 2011;14(1):167-172. Available from: https://www.iasj. net/iasj?func $=$ fulltext\&aId $=50451$ [ Acessed 21st Dec 2015].
7. Kleinerman RA. Cancer risks following diagnostic and therapeutic radiation exposure in children. Pediatr Radiol 2006;36 Suppl 2:121-125. https://doi.org/10.1007/s00247-006$\underline{0191-5}$

8. SinHK, Wong CS, Huang B, Yiu KL, Wong WL, Chu YC. Assessing local patients' knowledge and awareness of radiation dose and risks associated with medical imaging: a questionnaire study. $J \mathrm{Med}$ Imaging Radiat Oncol 2013;57(1):38-44. https://doi.org/10.1111/j.17549485.2012.02471.x

9. Soye JA, Paterson A. A survey of awareness of radiation dose among health professionals in Northern Ireland. $\mathrm{Br} \quad J$ Radiol 2008;81(969):725-729. https://doi.org/10.1259/bjr/94101717

10. Madrigano RR, Abrão KC, Puchnick A, Regacini R. Evaluation of non-radiologist physicians' knowledge on aspects related to ionizing radiation in imaging. Radiol Bras 2014;47(4):210-216. https://doi.org/10.1590/0100$\underline{3984.2013 .1840}$ 